\title{
EnganCHADos-Bebedjia hospital (Chad) and Fuenlabrada hospital (Madrid): improving surgical care in gynecological oncology
}

Rosa Montero-Macías (1) , Paris, France, Fuenlabrada, Spain; Elisabeth Raule, Fuenlabrada, Spain, Bebejia, Chad; Javier De La Torre González, Fuenlabrada, Spain, Fuenlabrada, Spain; Daniel Huerga Alvárez, Fuenlabrada, Spain, Fuenlabrada, Spain and Alfonso Antequera Pérez, Fuenlabrada, Spain, Gibraltar, United Kingdom

The Republic of Chad is the fifth largest country in Africa and the third poorest in the world. It is the country with the highest Gender Inequality Index in the world, making women a population especially at risk. ${ }^{1}$ Breast and cervical cancer rank among the highest in cancer incidence and mortality in many lowincome countries. Cervical cancer is the most commonly diagnosed cancer in 28 countries and the leading cause of cancer death in 42 countries in the world, the vast majority of which are in SubSaharan Africa. ${ }^{2}$ According to the Cancer Country Profile 2014 of the World Health Organization (WHO), breast, cervical, and ovarian cancer are the leading causes of death from cancer among Chadian women. Nevertheless, there are no data available regarding screening, cancer treatment, or palliative care in Chad. ${ }^{3}$

Surgical and anesthesia care are essential for the treatment of these diseases; however, access to surgical care is disparate and grossly inadequate in low-income countries contributing to significant preventable morbidity and death. ${ }^{4}$

The EnganCHADos project was started in 2014 as an initiative of $\mathrm{Dr}$ Alfonso Antequera. after a request for help from the missionaries. The collaboration started officially in 2015, with the signing a partnership agreement. Since then regular short-term missions, including physicians, nurses, and allied health professionals from Fuenlabrada University Hospital (Madrid) travel to Bebedjia to monitor the different services and give on-site training to the local staff at St Joseph Hospital (Figure 1). Our aim is to increase surgical expertise at Saint Joseph Hospital and improve access to

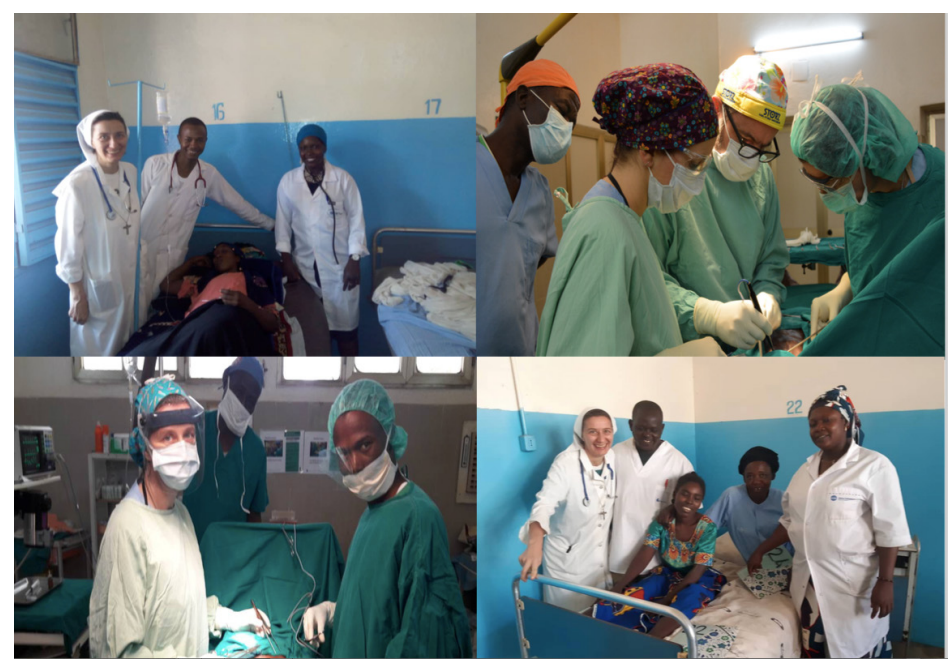

Figure 1 Local and EnganCHADos surgical team in St Joseph Hospital, Chad. adequate surgical care. In this pioneer agreement in the Spanish national health system, the Fuenlabrada University Hospital commits itself to providing support to Saint Joseph Hospital in terms of drugs, hospital equipment, and training to increase local surgical skills and medical knowledge. ${ }^{5}$

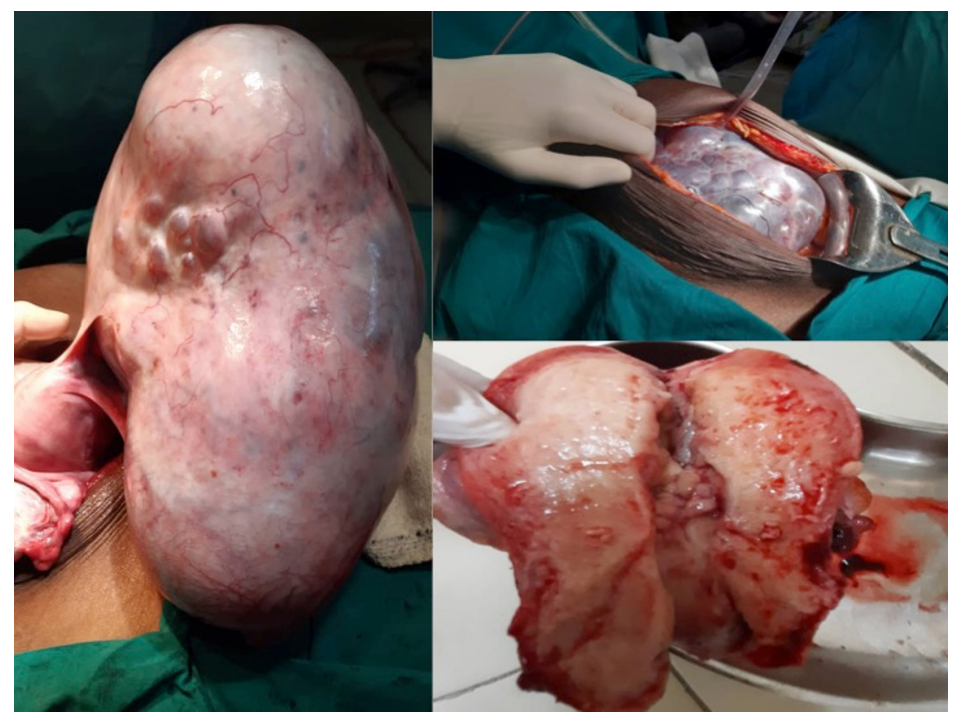

Figure 2 Gynaecological Oncologic surgeries in a low resources hospital (Saint Joseph Hospital (Bebedjia, Chad)). 


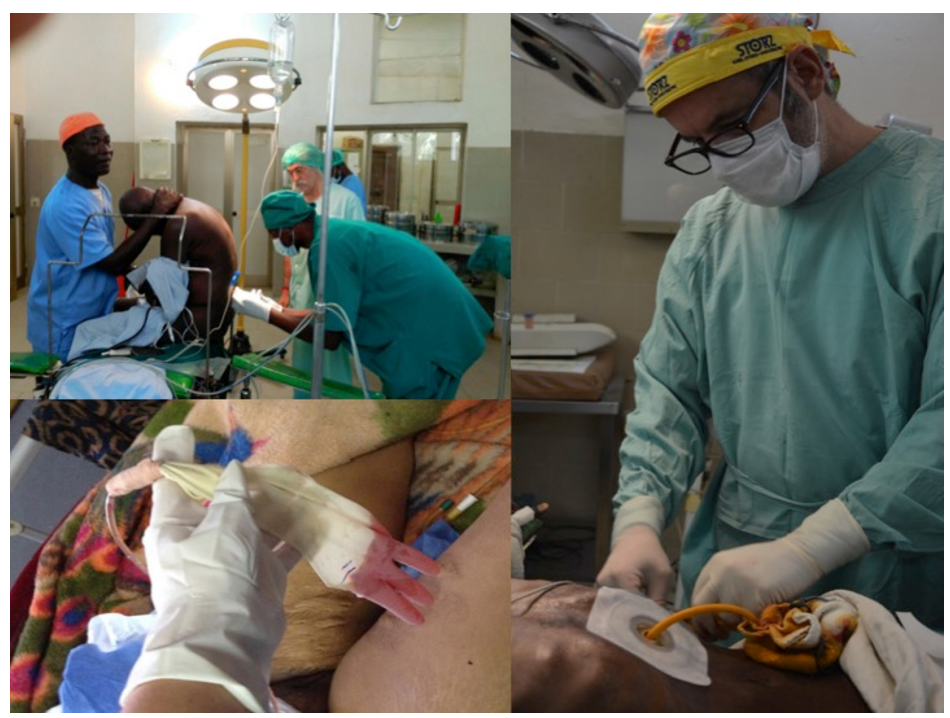

Figure 3 Pre and post-operative care in a low resources hospital (Saint Joseph Hospital (Bebedjia, Chad)).

The local surgeon, Dr Elisabeth Raule, performs approximately 600 surgeries per year. Among them, at least 50 are for gynecological cancer (Figure 2). The EnganCHADos visiting surgeons support local staff in performing operations during the missions, proctoring surgeons there to follow the WHO surgical safety standards. The diagnosis and treatment of gynecological cancers in this hospital setting is very challenging. Generally, the diagnosis is based on just clinical findings and ultrasound. The surgical care is one of the best in the country thanks to Dr Raule's skills and knowledge. Open surgery and local and general anesthesia are based on the use of ketamine, due to the lack of oxygen and ventilator support. Post-operative care is hazardous due to the lack of an adequate post-operative care unit (Figure 3). In addition, there is no possibility of adjuvant treatment due to the absence of radiotherapy or intravenous chemotherapy. Sometimes some drug donations allow short courses of oral chemotherapy.

Projects like EnganCHADos are helping to improve surgical and post-operative care of gynecological cancers in low-income countries. Ideally, in the future, screening policies and adjuvant treatments should be promoted. More hospitals in western countries should join developing hospitals in exchanging knowledge and sharing medical supplies and their work force, making the meaning of the 'cooperation' a true reality.

Correspondence to Dr Rosa Montero-Macías, Gynecologic and Breast Oncologic Surgery Department, European Hospital Group GeorgesPompidou, Paris 75908, France; rosaomsi@hotmail. com

Acknowledgements We appreciate the collaboration of all donors and staff of Fuenlabrada Hospital and Bebejia Hospital that make this project possible.

Collaborators David Montes Bentura; Paula Peña Moneva; Rocio Canete Riaza
Contributors RM and AA conceived the idea of writing this report and all the authors have contributed to the writing and final approval of this manuscript.

Funding EnganCHADos work is carried out thanks to multiple donors including the Fuenlabrada Hospital and the Fuenlabrada City Council.

Competing interests None declared.

Patient consent for publication Not required.

Provenance and peer review Not commissioned; internally peer reviewed.

(C) IGCS and ESGO 2020. No commercial re-use. See rights and permissions. Published by BMJ.

\section{Check for updates}

To cite Montero-Macías R, Raule E, De La Torre González J, et al. Int J Gynecol Cancer 2020;30:1644-1645.

Accepted 13 April 2020

Published Online First 14 June 2020

Int J Gynecol Cancer 2020;30:1644-1645.

doi:10.1136/ijgc-2020-001437

\section{ORCID iD}

Rosa Montero-Macías http://orcid.org/0000-00028159-2903

\section{REFERENCES}

1 Conceiçao P. Beyond income, beyond averages, beyond today: inequalities in human development in the 21st century. human development report 2019. United Nations Development Programme (UNDP).

2 Bray F, Ferlay J, Soerjomataram I, et al. Global cancer statistics 2018: GLOBOCAN estimates of incidence and mortality worldwide for 36 cancers in 185 countries. CA Cancer J Clin 2018;68:394-424.

3 World Health Organization. Geneva, Switzerland: Cancer Country Profiles: Chad, 2014. Available: https://www.who.int/ cancer/country-profiles/tcd_en.pdf?ua=1

4 Meara JG, Leather AJM, Hagander L, et al. Global surgery 2030: evidence and solutions for achieving health, welfare, and economic development. Lancet 2015;386:569-624.

5 Fundación El Compromiso. proyecto EnganCHADos (2020). Madrid, Spain: EnganCHADos. Available: https://www. enganchados.org/ 